Open Access

\title{
Effects of adrenomedullin on the expression of inflammatory cytokines and chemokines in oviducts from women with tubal ectopic pregnancy: an in-vitro experimental study
}

\author{
Hang Wun Raymond $\mathrm{Li}^{1,3^{*}}$, Su-Bin Liao ${ }^{1,2,3}$, Philip Chi Ngong Chiü,3 William Shu Biu Yeung ${ }^{1,3}$,
}

Ernest Hung Yu Ng ${ }^{1,3}$, Annie Nga Yin Cheung ${ }^{4}$, Fai Tang ${ }^{2,5}$ and Wai Sum $\mathrm{O}^{1,2,3}$

\begin{abstract}
Background: The occurrence of tubal ectopic pregnancy (tEP) is related to the inflammation of the oviduct. Recently, Adrenomedullin (ADM) was found highly expression in human oviduct. The current study is to investigate whether ADM have a modulatory action on inflammatory cytokines and chemokines in oviductal tissue from women with tubal ectopic pregnancy (tEP).

Methods: Oviductal isthmus samples were collected from women with tEP undergoing salpingectomy, and women undergoing hysterectomy for benign gynaecological conditions. The mRNA and protein levels of inflammatory cytokines/chemokines were assayed by PCR ( $n=6$ for tEP, $n=5$ for controls) and protein microarray methods ( $n=5$ for both tEP and controls) respectively.

Results: Some of the inflammatory cytokines/chemokines were upregulated by ADM in oviducts from tEP patients at both mRNA and protein levels. Incubation of oviduct from tEP patients with ADM for $24 \mathrm{~h}$ down-regulated some of these cytokines/chemokines.

Conclusion: Our results suggest an additional mechanism whereby ADM insufficiency may increase the susceptibility to tEP through diminished anti-inflammatory activity. The actual impact of the relationship between ADM and inflammatory process on tubal implantation needs further exploration.
\end{abstract}

Keywords: Adrenomedullin, Inflammatory cytokines, Chemokines, Tubal ectopic pregnancy

\section{Background}

Tubal ectopic pregnancy (tEP) occurs when an embryo implants in the oviduct. This is a major life-threatening health issue but the underlying causes remain unclear. Adrenomedullin (ADM) is a peptide hormone abundantly expressed in the human oviduct [1]. Recent studies in our laboratory showed that the oviduct produced a significant

\footnotetext{
* Correspondence: raymondli@hku.hk

'Department of Obstetrics and Gynaecology, The University of Hong Kong,

Queen Mary Hospital, Pokfulam Road, Hong Kong, Hong Kong

${ }^{3}$ Centre of Reproduction, Development and Growth, The University of Hong

Kong, Pokfulam Road, Hong Kong, Hong Kong

Full list of author information is available at the end of the article
}

amount of ADM and the ADM level was highest in the isthmic region in a hormonal environment simulating the early luteal phase [1]. A lower ADM expression found in the oviducts from $\mathrm{tEP}$ caused a decrease in ciliary beating frequency [2,3] and contraction [2] to impair oviductal transport of embryos, leading to embryo retention in the oviduct. As the retention of blastocysts in the oviduct [4] and haploinsufficency for ADM [5] does not result in tEP in the mouse, our observations suggest that there may be other concomitant alterations in the human oviducts, not present in animal models, to permit implantation at the ectopic site. 
Implantation requires regulated local expression of pro- and anti-inflammatory cytokines, chemokines, adhesion molecules and angiogenic factors [6], and involves a series of events including a change from an initial proinflammatory environment to an anti-inflammatory one. Proinflammatory cytokines and chemokines, as well as angiogenic factors, were induced by trophoblasts in the endometrium to facilitate implantation [7]. Cytokines, particularly those in the IL-6 family, play a significant role in establishing a pro-implantation environment in the uterus [8]. On the other hand, anti-inflammatory mediators are important at a later stage of implantation. . For instance, IL-10 and adiponectin are required to reduce inflammation and to promote fetal and placental growth [9].

Epidemiological studies indicate that pelvic infection is the major risk factor for tEP [10] and pelvic inflammatory diseases account for $20-40 \%$ of all cases of tEP in the United Kingdom [11]. Chlamydia trachomatis remains one of the most common pathogens in pelvic infections. C. trachomatis infection is usually asymptomatic and in the upper reproductive tract it can predispose the patient to tEP [12]. Other than C. trachomatis, pelvic inflammatory disease can be caused by Neisseria gonorrhoeae and anaerobic and mycoplasmal bacteria [13], leading to severe tubal damage, ectopic pregnancy, infertility and hydrosalpinx [14].

ADM has well-known anti-inflammatory actions [15] and its level is increased in a coordinated fashion in experimental and clinical conditions of inflammation and sepsis [16]. It reduces the production of pro-inflammatory cytokines including interferon (IFN)-gamma $[17,18]$ and various chemokines [19]. Therefore, we hypothesize that the decrease of oviductal ADM level may contribute to the pathogenesis of tEP by rendering the tubal environment more susceptible to inflammation, which then favors embryo implantation in the oviduct. This is in addition to another mechanism of action of ADM on pathogenesis of tEP proposed earlier by us, namely, impairment in oviductal transport of the embryo [2].

The objectives of this study was to find out whether the reduction of ADM expression in $\mathrm{EEP}$ is related to the changes in the inflammatory environment by studying the effect of ADM on the expression profile of inflammatory cytokines and chemokines in the oviducts with ectopic pregnancy. Such data are as yet not available in the literature.

\section{Methods}

\section{Subject recruitment and sample collection}

The isthmic parts of oviducts were collected from women undergoing hysterectomy for benign gynaecological diseases not involving the oviduct (control group; median age 50 years, range $45-54$ years), as well as women undergoing salpingectomy for tEP not involving the isthmic part (median age 32 years, range 25-39 years, mean gestational age $7.3 \pm 0.3$ weeks), at Queen Mary Hospital, Hong Kong. Subjects with suspected or confirmed malignancy or pelvic infection were excluded. Those with tEP found involving the isthmic region were also excluded intraoperatively as the whole specimen would be sent for histopathological diagnosis. In the absence of oviduct samples from normal pregnancy women due to ethical reason, the tissues obtained by hysterectomy were used as controls after priming with $10000 \mathrm{IU} / \mathrm{L}$ hCG, $4000 \mathrm{pmol} / \mathrm{L}$ estradiol and $50 \mathrm{nmol} / \mathrm{L}$ progesterone for $16 \mathrm{~h}$ to simulate the hormone environment of first trimester pregnancy, as reported in a previous study [2]. All recruited subjects had not received any hormonal treatment within 3 months prior to surgery.

\section{Ethics, consents and permissions}

Ethics approval was obtained from the Institutional Review Board of the University of Hong Kong/Hospital Authority Hong Kong West Cluster. Written consent was sought from the subjects during pre-operative counseling.

\section{Tissue preparation}

After collection, the oviductal tissue was immersed in ice-cold DMEM/F12 with 10 \% FBS (Invitrogen, Carlsbad, CA) and processed in the laboratory within $24 \mathrm{~h}$. After washing several times in DMEM/F12 culture medium to remove all visible blood, the oviducts were incubated in estradiol, progesterone and human chorionic gonadotropin (hCG) for use as controls as described above. To study the effect of ADM, the oviducts from patients with tEP were incubated with $100 \mathrm{nM}$ ADM (the dose used in our previous functional studies, [1, 2, 20-22] for $24 \mathrm{~h}$. The mRNA expression of five selected genes in the oviductal tissues from the control group and the tEP groups with and without ADM treatment were determined by realtime quantitative PCR, and the protein expression of inflammatory cytokines/chemokines were measured by a cytokine microarray method as detailed below.

\section{Measurement of gene expression of inflammatory cytokines/chemokines and their receptors by PCR microarray method}

Total RNA was extracted from the oviducts of normal control $(n=5)$ and those from tEP $(n=6)$ with or without ADM treatment using TRIZOL reagent (Invitrogen, Carlsbad, CA), and was then purified using the Qiagen RNeasy Mini Kit. Purity of the RNA samples was confirmed by an A260/A280 ratio between 1.8 and 2.0 on an UV spectrophotometer. Genomic DNA was removed by incubating with an elimination mixture (DNase I, $5 \mathrm{x}$ gDNA elimination buffer) at $42{ }^{\circ} \mathrm{C}$ for $5 \mathrm{~min}$. Reverse transcription was performed using the $\mathrm{RT}^{2}$ first strand 
Kit (Sabioscience company) according to the package insert. Real time PCR was performed for five selected genes (GM-CSF, IL-2, IFN-gamma, ENA78 and MIG) using the iCycler ${ }^{\mathrm{Tm}}$ (Bio-Rad Laboratories, Hercules, CA, USA) under the following conditions: $95{ }^{\circ} \mathrm{C}$ for $10 \mathrm{~min}$ for initial activation, followed by 40 cycles of denaturation at $95{ }^{\circ} \mathrm{C}$ for $30 \mathrm{~s}$, annealing at $57^{\circ} \mathrm{C}$ for 30 s, and extension at $72{ }^{\circ} \mathrm{C}$ for 30 s. G6PDH was used as the housekeeping gene. The mRNA expression of the studied genes was quantitated by the 2-ddCt method. The primers used were as follows:

GM-CSF (NM_000758): Forward 5' CACTGCTGCTG AGATGAATGAAA 3', Reverse 5' GTCTGTAGGCAG GTCGGCTC 3';

IL-2 (NM_000586): Forward 5' CATTGCACTAAGT CTTGCACTTGTCA 3', Reverse 5' CGTTGATATTGC TGATTAAGTCCCTC 3';

IFN-gamma(NM_000619): Forward 5' TCCCATGGG TTGTGTGTTTA 3', Reverse 5' AAGCACCAGGCATG AAATCT 3';

ENA78 (NM_002994): Forward 5' TGGACGGTGGAA ACAAGG3', Reverse 5'CTTCCCTGGGTTCAGAGAC 3';

MIG (NM_002416): Forward 5'GCATCATCTTGCT GGTTCTGATTGG 3'; Reverse 5'GCGACCCTTTCTC ACTACTGGGGT 3'.

G6PDH (NM_000402): Forward 5'-ATC GAC CAC TAC CTG GGC AA-3'; Reverse 5' -TTC TGC ATC ACG TCC CGG A-3'.

The five studied genes were selected as representative members of proinflammatory cytokines and chemokines.

\section{Measurement of cytokine/chemokine protein expression by antibody array method}

Upon confirming the differential mRNA expression of the representative pro-inflammatory cytokines and chemokines in tEP versus controls and the modulating effect of ADM, we further studied the cytokine/chemokine expression at the protein level using the RayBio Human Cytokine Antibody Array C5 (RayBiotech, Inc. GA), which detected 80 human cytokines/chemokines (Additional file 1: Table S1). Briefly, the protein of the samples (control: $n=5$; tEP: $n=5$ ) was extracted using the 2X RayBio Cell Lysis Buffer. After centrifugation, the supernatant was collected and the protein concentration was measured using Protein Assay Reagent (BioRad, Hercules, CA). The protein sample $(200 \mu \mathrm{g})$ was transferred to an antibodyarray membrane by electroplotting. The antibody-array membrane was blocked using $1 \mathrm{x}$ blocking buffer for $30 \mathrm{~min}$ at room temperature. After 3 washes, the membrane was incubated with $2 \mathrm{ml}$ biotin-conjugated anticytokine antibodies for $2 \mathrm{~h}$ at room temperature. Then, $2 \mathrm{ml}$ of 1000 -fold diluted horseradish peroxidase (HRP)conjugated streptavidin was added and incubated for $2 \mathrm{~h}$ to allow the streptavidin to attach to the biotin. After washing, the membrane was treated with the detection buffer for HRP for $2 \mathrm{~min}$. After the excess detection buffer had been drained off, the membrane was covered by two pieces of plastic sheets before exposure to X-ray film to develop the signals. The intensities of the dot signals were calculated using the Image J software.

\section{Statistics}

The relative mRNA and protein expressions of inflammatory cytokines and chemokines were compared between control and tEP samples using Mann-Whitney $U$ test, and those between tEP samples with and without ADM treatment were compared using Wilcoxon signed rank test. Statistical analysis was carried out using the IBM SPSS Statistics 20 software (IBM Corporation, New York, USA). A P value of $<0.05$ was taken to indicate statistical significance.

\section{Results}

Effect of ADM treatment on mRNA expression of selected cytokines/chemokines

The mRNA expression of 5 selected inflammatory cytokine/chemokine genes, namely GM-CSF, IL-2, IFN-gamma, ENA-78 and MIG, was compared between tEP versus control oviductal tissue, as well as in tEP oviductal tissue with and without ADM treatment, as shown in Fig. 1. Statistically significant up-regulation of mRNA expression $(p<0.05)$ in tEP compared to control was evident in only 2 of the 5 studied genes, namely GMCSF and IFN-gamma although an apparently increased expression of the rest was seen. Upon ADM treatment in the tEP tissue, significant lowering of mRNA expression to a level similar to the non-tEP control was found in 4 of the 5 studied genes, namely GM-CSF, IL-2, IFNgamma and ENA-78 $(p<0.05)$.

\section{Differential cytokine/chemokine expression at protein level in tEP oviducts as compared to control oviducts} Eight of the cytokines studied for their protein expression significantly increased in tEP oviducts compared to control are listed in Table 1. Four of these (GM-CSF, IL-7, IFN-gamma and TNF-beta) were pro-inflammatory cytokines, two (IL-10 and HGF) were anti-inflammatory cytokines and two (IL-4 and IL-6) could have either pro- and anti-inflammatory properties under different pathophysiological conditions [23].

\section{ADM treatment modulates the cytokine/chemokine expression in tEP oviducts}

ADM treatment for 24 h significantly $(P<0.05)$ reduced the levels of 7 out of the 8 cytokines that were upregulated in tEP (Table 1), except for IFN-gamma. Another four pro-inflammatory cytokines (IL-1 $\beta$, IL-3, IL-8 and VEGF) and seven chemokines (GRO- $\alpha$, MCP-1, MIP-1 $\beta$, 

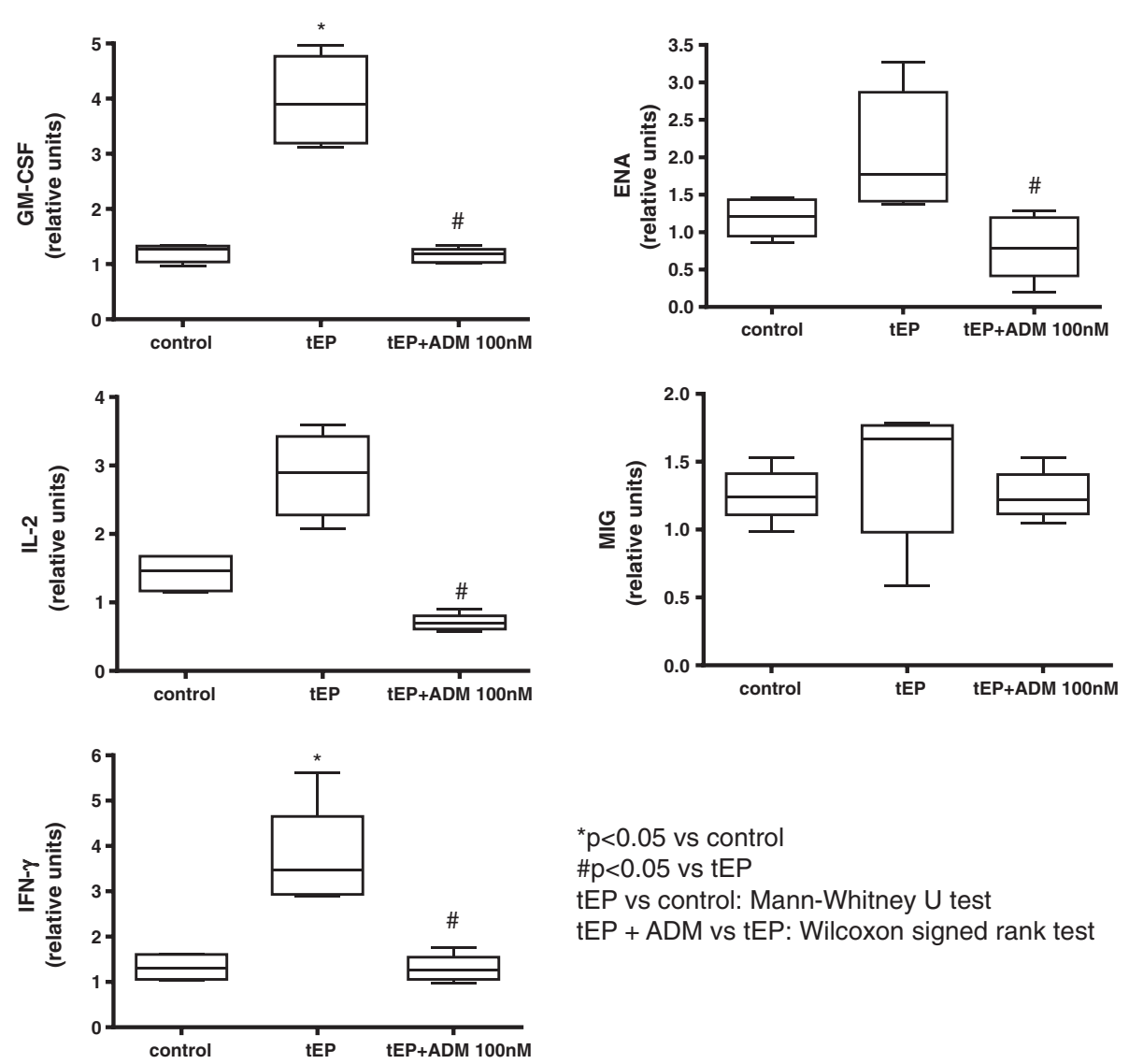

${ }^{*} \mathrm{p}<0.05$ vs control $\# p<0.05$ vs tEP tEP vs control: Mann-Whitney $U$ test tEP + ADM vs tEP: Wilcoxon signed rank test

Fig. 1 Comparison of mRNA expression of five selected inflammatory cytokines between tubal ectopic pregnancy (tEP) oviducts and control, and the effect of ADM on the expression of these cytokines. $\left({ }^{*} P<0.05\right.$, Mann-Whitney $U$ test; $\# P<0.05$, Wilcoxon signed rank test)

Table 1 The effect of ADM treatment on the up-regulated cytokines in tubal ectopic pregnancy (tEP) oviducts $(N=5)$

\begin{tabular}{|c|c|c|c|c|c|}
\hline \multirow[t]{2}{*}{ Symbol } & \multirow[t]{2}{*}{ Protein name } & \multicolumn{2}{|l|}{ tEP vs control } & \multicolumn{2}{|c|}{ tEP + ADM vs tEP } \\
\hline & & Fold change & $P$ value^ & Fold change & $P$ value\# \\
\hline \multicolumn{6}{|c|}{ Pro-inflammatory cytokines } \\
\hline GM-CSF & Granulocyte-macrophage colony-stimulating factor & 2.5173 & $0.032^{*}$ & 0.3204 & $0.032^{*}$ \\
\hline $\mathrm{IL}-7$ & Interleukin 7 & 2.5057 & $0.032^{*}$ & 0.2167 & $0.043^{*}$ \\
\hline IFN-gamma & Interferon-gamma & 2.1281 & $0.032^{*}$ & 0.5332 & 0.080 \\
\hline TNF-beta & Tumour necrosis factor-beta & 1.8817 & $0.016^{*}$ & 0.4897 & $0.043^{*}$ \\
\hline \multicolumn{6}{|c|}{ Anti-inflammatory cytokines } \\
\hline IL-10 & Interleukin 10 & 1.8760 & $0.008^{*}$ & 0.6194 & $0.043^{*}$ \\
\hline HGF & Hepatocyte growth factor & 1.5196 & $0.032^{*}$ & 0.7346 & $0.043^{*}$ \\
\hline \multicolumn{6}{|c|}{ Pro- and anti-inflammatory cytokines } \\
\hline $\mid \mathrm{L}-4$ & Interleukin 4 & 2.3493 & $0.032^{*}$ & 0.3941 & $0.043^{*}$ \\
\hline IL-6 & Interleukin 6 & 4.1152 & $0.016^{*}$ & 0.1135 & $0.043^{*}$ \\
\hline
\end{tabular}

Cytokines which were significantly up-regulated $(p<0.05)$ in tEP oviducts $(N=5)$ compared to controls $(N=5)$ are listed. To study the effect of ADM on the expression of these up-regulated cytokines, tEP oviducts were treated with $100 \mathrm{nM} \mathrm{ADM}$ for $24 \mathrm{~h}$. (*statistically significant, $P<0.05$; $\wedge$ Mann-Whitney $U$ test; \#Wilcoxon signed rank test) 
RANTES, Oncostatin, PDGF-B and NT-3), which were not significantly upregulated in tEP oviducts compared to control, were also suppressed by ADM treatment (Table 2). On the other hand, IL-1 $\alpha$, being not significantly altered in tEP compared to control, was significantly up-regulated by ADM treatment $(p<0.05)$.

\section{Discussion}

The major risk factors for tEP are tubal damage due to surgery or infection and smoking [24]. Based on our pilot study on mRNA expression of five representative inflammatory cytokines and chemokines, determination at the protein level was extended to a wider panel of 80 cytokines and chemokines using a commercial antibody array. We consider studying at the protein level more important as these are the effector molecules that exert the final biological and clinical actions. Our results demonstrated significantly higher protein expression of eight cytokines in the oviducts from tEP patients. These cytokines all play important roles in inflammatory processes. Most of these are pro-inflammatory although some have been recognized to have anti-inflammatory properties. It is the intricate balance the pro- and anti-inflammatory actions in the local tissue environment that dictates the ultimate inflammatory process within the tissue. Our results also showed that ADM treatment was able to reverse the up-regulation of most of these proteins in tEP. Our finding suggests an association between a reduced ADM expression and an increase in oviductal inflammatory activities in tEP.

Fertilization occurs in the ampullary region of the oviduct. In normal pregnancy, the embryo is transported by smooth muscle contraction and ciliary beating in the oviductal lumen [24-26]. Inflammation in the oviduct affects the tubal transport of embryos by decreasing ciliary activity and by increasing surface roughness and adhesion. For instance, the upregulation of TNF $\alpha$, a proinflammatory cytokine, following Gonococcal infection in the oviduct is associated with a decrease of ciliary activities [27] and sloughing of ciliated epithelial cells [28]. However, embryo retention in the tubal lumen alone may not be enough for the establishment of tEP. It has to be coupled with other local factors favoring tubal implantation [24]. In the context of uterine implantation, local inflammation initiated by signals from the implanting embryos in the endometrium is required for the establishment of a receptive endometrium and embryo adhesion [7]. Pro-inflammatory cytokines including IL-1, TNF, IL-6 and leukemia inhibitory factor (LIF) in particular have been detected at the fetal-maternal interface and are important in implantation [29]. Interestingly all these cytokines are induced in tubal infection [28, 30, 31]. Therefore, inflammatory activity in the oviduct appears to predispose the patient to tEP both by impairing tubal transport of the embryo and by favoring tubal implantation. Chemokines play important roles in both homing of leukocytes to specific regions within a tissue and activation of leukocytes. During peri-implantation period and early pregnancy in humans, the accumulation of leukocytes in the endometrium [32] mediated by uterine epithelial cells-derived chemokines [33] creates a local microenvironment permissive to implantation, tissue remodeling and embryo development.

As an additional evidence for the role ADM played in decreasing the levels of inflammatory cytokines/chemokines in $\mathrm{EEP}$, our results have demonstrated that exogenous ADM

Table 2 Cytokines/chemokines which were unaltered in tEP oviducts $(N=5)$ compared to controls $(N=5)$ but significantly suppressed by treatment with $100 \mathrm{nM}$ ADM for $24 \mathrm{~h}$

\begin{tabular}{|c|c|c|c|}
\hline Symbol & Protein name & $\begin{array}{l}\text { Fold change (tEP vs control) } \\
(P>0.05 \text { for all } \wedge)\end{array}$ & $\begin{array}{l}\text { Fold change (tEP }+ \text { ADM vs tEP) } \\
(P<0.05 \text { for all\#) }\end{array}$ \\
\hline \multicolumn{4}{|c|}{ Pro-inflammatory cytokines } \\
\hline IL-1 beta & Interleukin 1 beta & 1.7201 & $0.6993^{*}$ \\
\hline $\mathrm{IL}-3$ & Interleukin 3 & 1.3484 & $0.6483^{*}$ \\
\hline IL-8 & Interleukin 8 & 1.7410 & $0.2610^{*}$ \\
\hline VEGF & Vascular endothelial growth factor & 0.9642 & $0.3234^{*}$ \\
\hline \multicolumn{4}{|l|}{ Chemokines } \\
\hline GRO-alpha & Growth regulated alpha protein & 1.6460 & $0.2310^{*}$ \\
\hline MCP-1 & C-C motif chemokine 2 & 1.6450 & $0.5153^{*}$ \\
\hline MIP-1beta & C-C motif chemokine 4 & 1.5562 & $0.6020^{*}$ \\
\hline RANTES & C-C motif chemokine 5 & 1.2964 & $0.7014^{*}$ \\
\hline Oncostatin & Oncostatin & 1.3642 & $0.7404^{*}$ \\
\hline PDGF-B & Platelet-derived growth factor subunit B & 0.9040 & $0.6713^{*}$ \\
\hline NT-3 & Neurotrophin 3 & 1.4180 & $0.7097^{*}$ \\
\hline
\end{tabular}

(*statistically significant, $P<0.05 ; \wedge$ Mann-Whitney $U$ test; \#Wilcoxon signed rank test) 
abrogated the tEP-associated upregulation of cytokines (Table 1). Increasing evidence suggests that ADM is an immunomodulator with both pro-and anti-inflammatory activities [34]. ADM inhibits cytokine expression or release in cultured endometrial cells [20]. ADM may switch off the inflammatory response by regulating innate immunity at several critical levels [14] including the reduction in the production of pro-inflammatory cytokines such as IFN-gamma [16], TNF-alpha, IL-6 and IL-1 [18] and various chemokines [19]. The present study has added to the list several cytokines and chemokines which may also be regulated by ADM. As ADM expression is generally reduced in patients with tEP [2], this ADM insufficiency may result in a tubal environment conducive to inflammatory activities and tubal implantation, hence contributing to the pathogenesis of tEP.

In our study, we used oviducts removed from nonpregnant women during hysterectomy as controls. Although these tubal samples were conditioned to a standard hormonal environment to simulate early pregnancy, it may be arguable whether it truly represents oviducts during early intrauterine gestation. However, as oviducts from normal pregnant women could not possibly be obtained for ethical reasons, our model is the best practically available option. Nonetheless, this should not have affected the main theme of our study on the effect of ADM on the inflammatory cytokines/chemokines.

To our knowledge, this is the first report on the immune-modulatory effect of adrenomedullin in the human oviductal tissue. The main limitation of our study was the small sample size that we worked on because of the difficulty in obtaining more samples, which leads to the pilot nature of this work. Nonetheless, our result opens up an interesting avenue for further studying the role of ADM insufficiency in interaction with inflammatory activities in the pathogenesis of tEP.

\section{Conclusions}

We report for the first time the down-regulation of some inflammatory cytokines and chemokines in the tEP oviducts by ADM. This finding suggests an additional mechanism whereby ADM insufficiency may increase the susceptibility to tEP [2], apart from its effects on ciliary beating and muscle contraction [2] and also fluid secretion [22]. More studies on the immune-modulatory role of ADM in the pathogenesis of tEP are warranted.

\section{Additional file}

Additional file 1: Table S1. List of 80 cytokine and chemokine proteins/receptors measured by protein microarray in the oviducts from control group and women with tubal ectopic pregnancy (tEP), as well as those with tEP after adrenomedullin (ADM) treatment. (DOCX $26 \mathrm{~kb})$

\section{Competing interests}

The authors declare that they have no competing interests.

\section{Authors' contributions}

HWRL recruited study subjects, analysed the data and wrote the manuscript SBL performed the experiments and analysed the data. PCNC analysed the data and wrote the manuscript. WSBY and. EHYN planned the study and edited the manuscript. ANYC confirmed the pathological diagnosis. FT and WSO planned the study, analysed the data and edited the manuscript. All authors read and approved the final manuscript.

\section{Acknowledgements}

We thank Ms Joyce Yuen and other staff members of the Gynaecology Team, Queen Mary Hospital, for their assistance in patient recruitment and sample collection.

\section{Funding}

This work was supported by an Incentive Award from the University of Hong Kong. Part of the study was supported by a research grant from the General Research Fund, Research Grant Council, Hong Kong (project number: 17113314).

\section{Author details}

'Department of Obstetrics and Gynaecology, The University of Hong Kong, Queen Mary Hospital, Pokfulam Road, Hong Kong, Hong Kong. ${ }^{2}$ School of Biomedical Sciences, The University of Hong Kong, Pokfulam Road, Hong Kong, Hong Kong. ${ }^{3}$ Centre of Reproduction, Development and Growth, The University of Hong Kong, Pokfulam Road, Hong Kong, Hong Kong. ${ }^{4}$ Department of Pathology, The University of Hong Kong, Pokfulam Road, Hong Kong, Hong Kong. ${ }^{5}$ Centre of Heart, Brain, Hormone and Healthy Aging, The University of Hong Kong, Pokfulam Road, Hong Kong, Hong Kong.

Received: 23 July 2015 Accepted: 22 October 2015

Published online: 05 November 2015

\section{References}

1. Li HWR, Liao SB, Chiu PCN, Ng E, Yeung WSB, Ho JCM, et al. Expression of adrenomedullin in human oviduct, its regulation by the hormonal cycle and contact with spermatozoa and its effect on ciliary beat frequency of the oviductal epithelium. JCEM. 2010;95:E18-25.

2. Liao SB, Li HWR, Ho JC, Yeung WSB, Ng EHY, Cheung ANY, et al. 2012a Possible role of adrenomedullin in the pathogenesis of tubal ectopic pregnancy. JCEM. 2012;97:2105-12.

3. WS O, Li HWR, Liao SB, Cheung ANY, Ng EHY, Yeung WSB, et al. Decrease in adrenomedullin expression and ciliary beat frequency in the nasal epithelium in tubal pregnancy. Fert Steril. 2013;100:459-63.

4. Wang H, Guo Y, Wang D, Kingsley PJ, Marnett LJ, Das SK, et al. Aberrant cannabinoid signaling impairs oviductal transport of embryos. Nature Med. 2004;10:1074-80.

5. Li M, Wu Y, Caron KM. Haploinsufficiency for adrenomedullin reduces pinopodes and diminishes uterine receptivity in mice. Biol Reprod. 2008;79:1169-75.

6. Hutchinson $J$, Rajagopal SP, Sales KJ, Jabbour HN. Molecular regulators of resolution of inflammation: potential therapeutic targets in the reproductive system. Reproduction. 2011;142:15-28.

7. Hess AP, Hamilton AE, Wagner E, Dosiou C, Nyegaard M, Nayak N, et al. Decidual stromal cell response to paracrine signals from the trophoblast: amplication of immune and angiogenic modulators. Biol Reprod. 2007;76:102-17.

8. Van Mourik MS, Maclon NS, Heijjnen CJ. Embryonic implantation: cytokine, adhesion molecules, and immune cells in establishing an implantation environment. J Leukoc Biol. 2009;85:4-19.

9. Hanna N, Hanna I, Hleb M, Wagner E, Doughter J, Balkundi D, et al. Gestational age-dependent expression of IL-10 and its receptors in human placental tissues and isolated cytotrophoblast. J Immunol. 2000;164:5721-8.

10. Manavi K. A review of infection with Chlamydia trachomatis. Best Pract Res Clin Obstet Gynaecol. 2006;20:941-51.

11. Haggerty CL, Gottlieb SL, Taylor BD, Low N, Xu F, Ness RB. Risk of sequelae after Chlamydia trachomatis genital infection in women. $J$ Infect Dis. 2010;201:S134-55. 
12. Pientong C, Ekalaksananan T, Wonglikitpanya N, Swadpanich U, Kongyingyoes B, Kleebkaow P. Chlamydia trachomatis infections and the risk of ectopic pregnancy in Khon Kaen women. J Obstetet Gynaecol Res. 2009;35:775-81.

13. Haggerty CL, Ness RB. Epidemiology, pathogenesis and treatment of pelvic inflammatory disease. Expert Rev Anti Infect Ther. 2006;4:235-47.

14. Ajonuma LC, Chan PK, Ng EH, Fok KL, Wong CH, Tsang LL, et al. Involvement of cystic fibrosis transmembrane conductance regulator (CFTR) in the pathogenesis of hydrosalpinx induced by Chlamydia trachomatis infection. J Obstet Gynaecol Res. 2008;6:923-30.

15. Zudaire E, Portal-Núñez S, Cuttitta F. The central role of adrenomedullin in host defense. J Leukoc Biol. 2006;80:237-44.

16. Bunton DC, Petrie MC, Hillier C, Johnston F, McMurray JJ. The clinical relevance of adrenomedullin: a promising profile? Pharmacol Ther. 2004;103:179-201.

17. Talero E, Sánchez-Fidalgo S, de la Lastra CA, Illanes M, Calvo JR, Motilva V. Acute and chronic responses associated with adrenomedullin administration in experimental colitis. Peptides. 2008;29:2001-12.

18. Yang S, Zhou M, Fowler DE, Wang P. Mechanisms of the beneficial effect of adrenomedullin and adrenomedullin-binding protein-1 in sepsis: down-regulation of proinflammatory cytokines. Crit Care Med. 2002;30:2729-35.

19. Jin D, Otani K, Yamahara K, Ikeda T, Nagaya N, Kangawa K. Adrenomedullin reduces expression of adhesion molecules on lymphatic endothelial cells. Regul Pep. 2011;166:21-7.

20. Liao SB, Kong LHM, Tang F, WS O. Possible functions of adrenomedullin from the seminal fluid in the female reproductive tracts of the rat. Syst Biol Reprod Med. 2012;58:306-12.

21. Liao SB, Ho JC, Tang F, WS O. Adrenomedullin increases ciliary beat frequency and decreases muscular contraction in the rat oviduct. Reproduction. 2011;141:367-72.

22. Liao SB, Cheung KH, Cheung MPL, To YT, WS O, Tang F. Adrenomedullin increased the short-circuit current in the pig oviduct through chloride channels via the CGRP receptor: mediation by CAMP and calcium ions but not by nitric oxide. Biol Reprod. 2013;89:1-6.

23. Scheller J, Challaris A, Schmidt-Arras D, Rose-John S. The pro- and antiinflammatory properties of the cytokine interleukin-6. Biochem Biophys Acta. 2011;1813:878-88.

24. Shaw IL, Dey SK, Crtichely HOD, Horne AW. Current knowledge of the aetiology of human tubal ectopic pregnancy. Hum Reprod Update. 2010;16:432-44.

25. Horne AW, Critchlely HOD. Mechanisms of disease: the endocrinology of ectopic pregnancy. Expert Rev Mol Med. 2012;14:e7.

26. Shaw JL, Horne AW. The paracrinology of tubal ectopic pregnancy. Mol Cell Endocrinol. 2012;358:216-22.

27. Vasquez G, Winston RM, Bronsens IA. Tubal mucosa and ectopic pregnancy. Brit J Obstet Gynaecol. 1983;90:468-74.

28. McGee ZA, Jensen RL, Clemens CM, Taylor-Robinson D, Johnson AP, Gregg CR. Gonococcal infection of human fallopian tube mucosa in organ culture: relationship of mucosal tissue TNF-alpha concentration to sloughing of ciliated cells. Sex Transm Dis. 1999;26:160-5.

29. Jabbour HN, Sales KJ, Catalano RD, Norman JE. Inflammatory pathways in female reproductive health and disease. Reproduction. 2009;138:903-19.

30. Hvid M, Baczynska A, Deleuran B, Fedder J, Knudsen HJ, Christiansen G, et al. Interleukin-1 is the initiator of Fallopian tube destruction during Chlamydia trachomatis infection. Cell Microbiol. 2007;9:2795-803.

31. Ji YF, Chen LY, Xy KH, Yao JF, Shi YF. Locally elevated leukemia inhibitory factor in the inflamed fallopian tube resembles that found in tubal pregnancy. Fertil Steril. 2009;91:2308-14.

32. Bulmer JN, Williams PJ, Lash GE. Immune cells in the placental bed. Int J Dev Biol. 2010;54:281-94.

33. Dimitriadis E, White CA, Jones RL, Salamonsen LA. Cytokines, chemokines and growth factors in endometrium related to implantation. Hum Reprod Update. 2005;11:613-30.

34. Wong LY, Cheung BM, Li YY, Tang F. Adrenomedullin is both proinflammatory and anti-inflammatory: its effects on gene expression and secretion of cytokines and macrophage micturation inhibitory factor in NR8383 macrophage cell line. Endocrinology. 2005;146:1321-7.

\section{Submit your next manuscript to BioMed Central and take full advantage of:}

- Convenient online submission

- Thorough peer review

- No space constraints or color figure charges

- Immediate publication on acceptance

- Inclusion in PubMed, CAS, Scopus and Google Scholar

- Research which is freely available for redistribution

Submit your manuscript at www.biomedcentral.com/submit 